\title{
Teachers' Perceptions of Customizing Students' Learning through Differentiated Instruction at a Tertiary level
}

\section{Munira Said Al Siyabi}

Department of English Language and Literature

University of Technology and Applied Sciences

Rustaq, Oman

Correspondent Author: DalalAl-Shekaili.rus@cas.edu.om

\section{Dalal Abdullah Al Shekaili}

Department of English Language and Literature

University of Technology and Applied Sciences

Rustaq, Oman

Received : 11/4/2020 Accepted: 3/5/2021 Published :3/24/2021

\begin{abstract}
Traditional ways of teaching were challenged by differentiated instruction which aims to embrace students' variance. Teachers are expected to maximize the learning opportunities by meeting the diverse needs of their learners. English teachers in Omani schools are trained and instructed to modify the content to meet students' different levels; however, teachers in higher education institutions are given more freedom in planning and conducting their classes. This research investigated teachers' perceptions of differentiated instruction which is customised to meet the diversity of learning needs and interests of English as foreign language students in the University of Technology and Applied Sciences-Rustaq (UTAS-Rustaq). The study also sought to identify practices teachers follow to implement differentiated instruction. An exploratory, descriptive analysis and a survey were employed to obtain the necessary data, which indicated that teachers are aware of differentiating instruction and the related practices. Teachers also showed a good understanding of the type of knowledge needed to obtain before implementing differentiation and the assessment tools to attain them. However, the results also indicate an essential need for structural support, professional development, to meet the challenges identified by teachers to maintain the continuity of these practices.
\end{abstract}

Keywords: Content, differentiated instruction, process, product, teachers' perception

Cite as: Al Siyabi, M. S., \& Al Shekaili, D. A. (2021). Teachers' Perceptions of Customizing Students' Learning through Differentiated Instruction at a Tertiary level. Arab World English Journal, 12 (1) 74 -387. DOI: https://dx.doi.org/10.24093/awej/vol12no1.25 
Arab World English Journal (AWEJ) Volume 12. Number 1. March 2021

Teachers' Perceptions of Customizing Students' Learning

Al Siyabi \& Al Shekaili

\section{Introduction}

As current classrooms are challenged with diversity in students' backgrounds and learning needs, the teaching boards are working hard to accommodate students' learning needs. Contemporary educational trends, as a result, are shifting focus from a one-size-fits-all design to a more personalized learning approach (Fox \& Hoffman, 2011). Teachers are constantly encouraged to pay attention to individual differences in their students. However, few teachers are aware of tailoring a lesson that respects students' diversity and responds to their various needs. Differentiation is a concept that has been found to effectively address all students' needs and assist them in achieving course objectives at their own pace. It empowers all students to invest their varying potential to attain class standards. Differentiation also refers to a teacher's proactive response to learner needs (Tomlinson \& Moon, 2013). The main principle of differentiation is that all students should achieve the same objectives. Thus, standardisation can be aligned with differentiation (McTighe \& Brown, 2010).

This study aims to investigate teachers' perceptions of differentiated instruction in the Department of English Language and Literature (ELL) in UTAS-Rustaq. It also seeks to examine teachers' awareness of the principles needed to maintain efficient implementation of differentiated instruction practice in their classes. ELL is running English teacher preparation program which is committed to prepare its prospective teachers to meet the standards of the Omani schools' system. ELL offers a Differentiated Learning and Independent Learning course to its fourth-year students to ensure a good comprehension of the concept. However, the current study investigates if the instructors in the department are adopting the principles of differentiation. The implementation of differentiated instruction by the instructors will not only assist them to meet their students' needs but it will provide an excellent example for the prospective teachers. In light of the essential need for differentiated instruction as discussed and the decisions that must be made to pave the way for differentiation, the following research questions guided this research:

1) What are English teachers' perceptions of implementing differentiated instruction?

2) What procedures are followed to implement differentiated instruction?

\section{Literature Review}

Differentiation as a term is interconnected to different classroom elements, and among them is instruction. Biggs (1999) defined instruction as "a construction site on which students build on what they already know" (as cited in Moon, 2005, p. 227). Teachers should ensure that new learning is taking place and provide support whenever needed. Tomlinson and Moon (2013) mentioned that 'instruction is at the core of differentiation' since the primary goal of differentiation is to give each student the best learning experience. Furthermore, Levy (2008) identified differentiated instruction as ways or strategies that help teachers to reach students at their current levels and help them advance from there. Levy (2008) also added that concerning student's readiness, interests, and learning profiles, differentiated instruction should aim to provide "flexibility in content, process, and product" (p. 162). Thus, teachers must make multiple decisions, including what to teach, how to teach it, and how to assess what is taught (Campbell, 2009). Corley (2005) declared that "the cornerstone of differentiation is active planning" (p.13). Appropriate assessment can be helpful for gathering essential and adequate information that enable teachers to make decisions on the proper content to teach and to inform the teaching process. 
Content is a component of instruction that can be differentiated to suit all students' current levels. Tomlinson and Moon (2013) referred to content as the knowledge and skills to which students need access. In a standardized system, teachers adhere to the course textbooks, which increase the difficulty of attending to students' individual needs. However, teachers may adjust the degree of complexity to suit the diverse needs of students (Hall, Strangman \& Meyer, 2003). In addition to adjusting content, teachers should have the authority to eliminate sections of the book from the course content if students cannot cope with that content. However, teachers should be careful that such elimination will not hinder students' ability to achieve the course objectives since they must pass the same examinations or meet the same standards (Levy, 2008). On the other hand, some students may be fast learners and may accomplish the objectives ahead of time. Teachers can provide these students with supplementary materials to make time to work with the other students.

The teaching and learning process reflects how teachers teach the subject and how students learn it. It involves the implementation of various activities to deliver and practice the presented content. Levy (2008) mentioned that teachers cannot follow one method for teaching all students since they all learn in different ways. Teachers should always vary the learning activities provided to students to meet the broad range of readiness, interests, and learning profiles in their classrooms. Teachers can implement flexible grouping based on previously determined criteria to distribute different prepared activities appropriate for the diverse groups (Corley, 2005). Hall et al. (2003) stated that grouping must be a dynamic process, changing with the content, projects, and ongoing evaluations. Such flexible grouping will encourage diversity in the classroom and build good relations among students, too. Moreover, teachers' use of formative assessment or ongoing evaluation to check students' progress may enable them to vary the content and process based on the results.

Product is the third component of instruction that can be easily differentiated to demonstrate students' accomplishments and potential. It reflects what content and skills students have learned via pre-assessments, formative assessments, and summative assessments (Hall et al., 2003). The results of pre-assessments support the process of differentiating instruction and assist teachers in making decisions regarding instruction pacing, revision time, flexible grouping, and other components of differentiated instruction. Pre-assessment results also enable teachers to choose the appropriate level of challenge to sustain learning. Formative assessments provide teachers with information and feedback for planning future instruction that students can manipulate to boost their progress (Dodge, 2009). Summative assessments show how successful students were in learning what was taught or achieving the course learning outcomes. Summative assessments can vary from standard exams to projects or presentations, and they may be different from one student to another (Tomlinson \& Moon, 2013). Tomlinson (2000) pointed out that differentiating products can occur at the level of rubrics or grouping. Tomlinson and Allan (2000) stated that a good product encourages students to reflect on what they have learned and to get "involved in critical and creative thinking" (p. 5). Project-Based Learning (PBL) is one of the methods that respects and responds to students' diverse needs. It focuses on "engaging students in an investigation" (Blumenfeld et al., 1991, p. 371). This teaching method develops responsibility among students since they are in charge of creating their questions and designing the tasks required to solve them. Blumenfeld et al. (1991) also mentioned that PBL sets students 
in a real context where they need to solve a problem, which, in turn, enables them to acquire a better understanding of the underlying concepts and improve their critical thinking skills.

As previously noted, to maximize the potential benefits of differentiated content, process, and product, teachers should cater to learners' diversity in terms of readiness, interests, and learning styles. Studies have shown that students are successful if instruction is responsive to these criteria (Corley, 2005). Readiness, which is a cornerstone of efficient learning, is linked to the 'zone of proximal development' proposed by Vygotsky (1978, 1986). It suggests that learners learn better when introduced to a moderate challenge. However, designing one task for varying levels of readiness fails to facilitate learning for many students whose readiness level is beyond or below the level required for the task. In short, tasks must be at the appropriate level of difficulty to maintain their motivating force for different students (National Research Council, 1996).

Just as readiness must be considered to promote better academic performance, so, too, must interest be taken into account. Modifying instruction to meet the interests of individual students positively affects their learning progress (Renninger, 1998). Amabile (1996) claimed that providing students with a chance to do something they like improves their learning attitude.

Responding to students' different learning styles is equally beneficial. Learning styles refer to individual preferences within specific categories, such as emotions, interactions and environment (Dunn \& Griggs, 1998).

Thus, differentiated instruction is a response to the academic diversity that teachers must consider in order to ensure an effective learning experience for each individual student (Tomlinson et al., 2003). Differentiated instruction invites creativity and respects the diversity of individuals (Strassman, 2005). It makes the teaching and learning process more rewarding for both teacher and student. Teachers will not have a negative attitude about the apparent differences in students' abilities because they approach the class prepared with a strategic plan to respond to the students' diversity.

However, despite the great deal of literature on the vital role played by differentiated instruction, very little is known about teachers' views in the Omani context. This paper aims at addressing teachers' perceptions of differentiation and their current practices to implement it at UTAS-Rustaq.

\section{Method}

This exploratory descriptive study, conducted at UTAS-Rustaq, examined teachers' perceptions of differentiated instruction and the potential for customising learning in response to the variability of their EFL students.

\section{Participants}

The Department of English Language and Literature (ELL) included approximately 33 faculty members. Besides the main courses offered to English language major students, the department offers the foundation program for all English language major students and two general English courses for all students in other majors. Thus, most instructors were experienced in teaching English language courses and courses that focused on different aspects of the English 
language and were knowledgeable about the related teaching methodologies. Having the opportunity to teach students across a span of years provided these instructors with good insight into the knowledge and skills with which they need to equip first-year students and English language majors in the foundation of their program. In addition, the ELL department conducts professional development sessions to share teaching experiences and raise the quality of learning. However, this practice is still in its elementary stage, as no needs analysis has been performed to identify teachers' needs and plan the sessions accordingly. Currently, it serves as a platform for teachers to share their research and teaching experiences.

\section{Instrument}

A 2-part survey was conducted to collect data from the English instructors at the UTASRustaq. The first part included three-point Likert scale questions intended to gather data to identify the general understanding of differentiated instruction among teachers. In the second part, participants were asked open-ended questions seeking information on the practices they currently follow in their classes to achieve customization. The analysis of the collected data was based on frequency and theme coding.

To improve its validity, the survey was checked by an experienced instructor and then piloted, and improvements were made based on the instructor's feedback. Zailinawati, Schattner \& Mazza (2006) indicated that piloting is an essential stage of survey administration, as it examines the clarity and appropriateness of the intended questions. After the improvements were made, the survey was then distributed to instructors, and 15 were completed.

\section{Results}

\section{The Provided Support}

To examine how teachers perceive differentiated instructions in their practice, it was crucial to find out about their perception of the support they receive from their department, English Language and Literature department, towards differentiation. Analysis of the collected data revealed that less than $50 \%$ of the teachers surveyed agreed that the ELL department supports their efforts to differentiate instruction in their classrooms. Teachers reported that they are asked to implement remedial plans to support students who are behind in achieving the learning outcomes without being given clear instructions on how to design or implement these remedial plans. The department does not generally interfere in teaching practices, yet it encourages teachers to cater to the needs of their students, according to survey results. Some respondents noted that the department does not provide much support due to the emphasis on textbook completion and large class size.

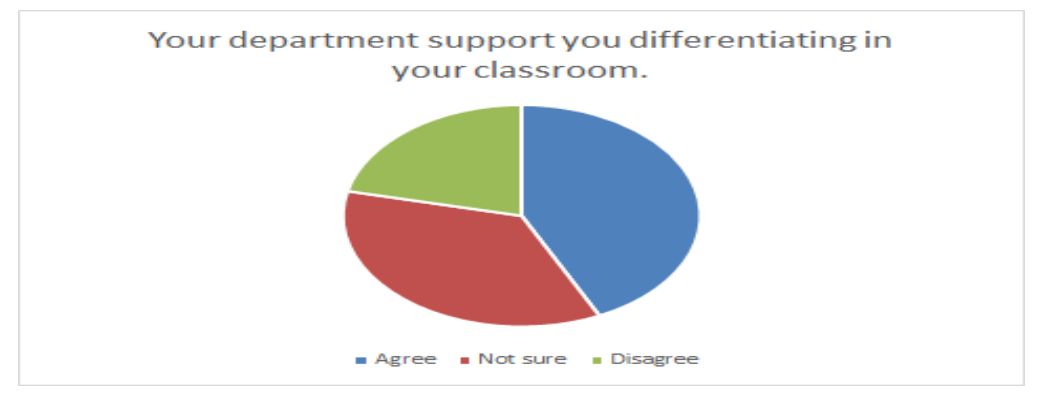

Figure 1. The departmental support 


\section{Teachers' General Perceptions of Differentiated Instruction}

Figure 2 illustrates the results of teachers' general perceptions of differentiated instruction. Despite reporting receiving insufficient support, the respondents held a positive attitude toward practicing differentiation in their classrooms. About $86 \%$ of the respondents agreed that differentiation enables them to achieve their course objectives. Thus, when asked about the impact of differentiation on students' performance, $80 \%$ of the respondents agreed that differentiated instruction does have a positive impact on student performance, while $20 \%$ were not sure. When teachers were asked about the positive impact of incorporating differentiated instruction, they stressed the same points discussed previously, including achieving the learning outcomes, interesting classes, and satisfaction amongst students. However, only $60 \%$ of the respondents agreed that it is possible to have high expectations for all students in the classroom with differentiated instruction, while some respondents stated that since differentiated instruction classes try to attend to students at all levels, much should be expected from each student. However, other responses called for the adjustment of expectations based on the level of the student. Most respondents identified time, the effort required, and the delay in achieving their objectives as the significant challenges that may make them reluctant to implement differentiated instruction.

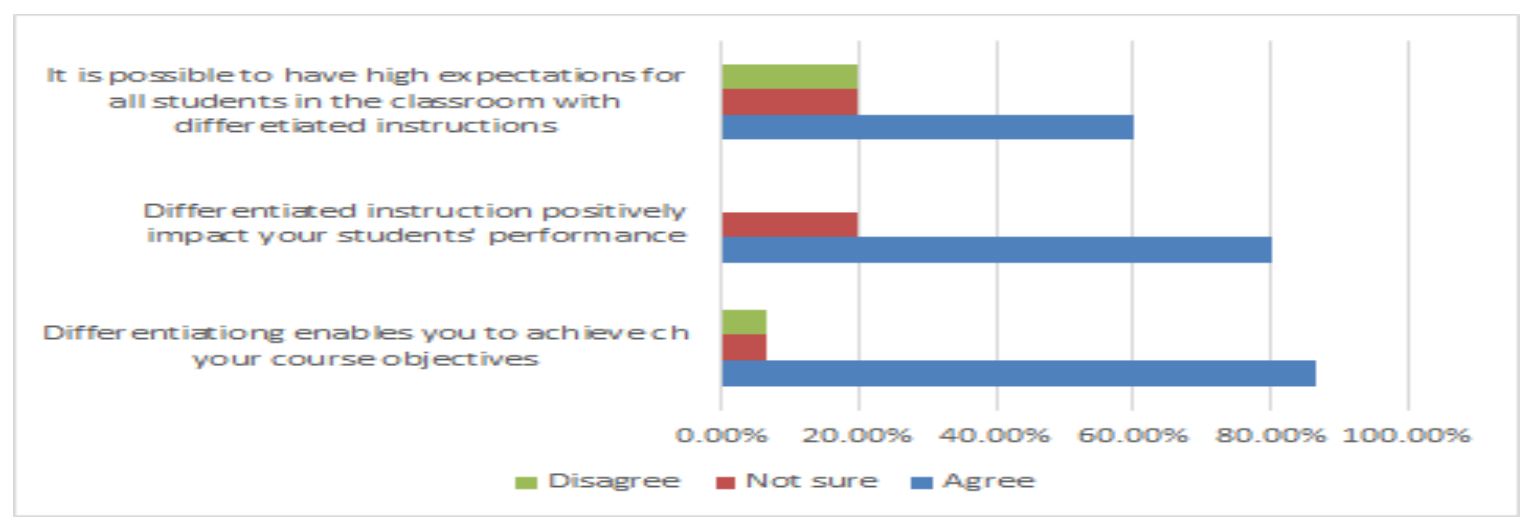

Figure 2. Teachers' perceptions of Differentiated instruction

\section{Applying the Principles of Differentiated Instruction}

The respondents shared similarities in identifying the needed information before applying differentiation. Some participants listed, "language level, abilities, Learning styles", "learner progress, strengths, weaknesses, learning styles", "Language proficiency", "readiness, progress, skills, interest" and "students' ability, level of commitment to check student autonomy, responsibility."

The respondents shared diverse techniques to collect the needed data about their students. Some participants stated,

"Sometimes through the interaction and participation", "Through tasks and activities", "exam results", "Short interviews: "Assessment such as a piece of writing or oral test to find out about their listening skills abilities", "Casual conversation, written output" and "Monitoring their work, assessing their outputs, getting students information for majors, tracing performance in class." 
The participants declared a varying level of success to meet the course objectives with differentiating on board. Some respondents reported,

"Using different materials/ activities that help learners to learn and achieve the target objectives", "Objectives are attained a bit slower owing to time constraints", "For as long as the course categories are met, it doesn't matter what process used to get there", "By taking step by step, clear instructions, by simplifying the tasks into more doable tasks" and "Pretty well, the class has clear parameters, and I stuck to them and encouraged some students to do more."

When the participants were asked about how they accommodate the students who fail to achieve the course objectives, the majority focus on giving extra tasks and time. Some of the listed actions are,

"Allocate specific time for them to check their understanding and guide them", "give extra work and motivate autonomous learning", "by giving them more activities (smart objectives), something easy that they can achieve", "giving office hours", and one respondent was curious about the reasons indicating that "it depends on why they are falling behind. Those who are trying to meet the program requirements, will get my help to create a pattern of success."

The majority of the participants activate grouping to incorporate differentiated instruction into their classrooms. The stated that they use,

"different types of activities (group work, pair work, individually)", "homogeneous grouping based on their interest, necessity, and capacity", "class is divided into segments or smaller units", "by dividing the class into different levels and giving each group different instruction", "prepare an activity for the main groups and have advanced task for the good students" and a participant emphasize the use of "different methods when delivering lessons to students".

When asked about how they assess their students' progress, the participants reported that they use, "one to one tutorials with each student in order to find out if the student has improved", "the quality of outputs, the progress of their performance" "oral non-credit feedback for the individual research projects", "assess them according to their capacity, level and learning outcomes."

\section{Discussion}

\section{The Provided Support}

Teachers need to adjust their teaching practices to ensure every student has an equal opportunity to learn (Tomlinson, 1997). However, teachers may be reluctant to implement differentiation without receiving adequate support from their institutions. It was apparent that teachers at UTAS-Rustaq were dissatisfied with the amount of support they receive from their respective departments. The lack of support, hence, affects the quality of teachers' performance. Gamoran et al. (2003) asserted that the support provided by institutions, including; the supplied materials, resources and quality professional development sessions provided for instructors, would increase the likelihood of tailoring instruction to meet the needs of students (as cited in Abbati, 2012). Nicolae (2014) argued that most teachers are open to differentiating instruction but are not skilled enough to implement the practice. Teachers need real support and commitment from their schools to enhance differentiated instruction practices, which "can take seven to ten years to institutionalize" (Hess, 1999, as cited in Nicolae, 2014, p. 429). Robinson 
(2004) emphasized the importance of having supportive teams and organisations to encourage the implementation of differentiated instruction in classrooms. This declaration reveals that designing and implementing instruction for varying levels is both challenging and complex. It requires collaborative work to facilitate the process; verbal instruction is not enough.

\section{Teachers' General Perceptions of Differentiated Instruction}

Teachers' positive attitude towards the efficiency of differentiated instruction in meeting the course objectives was similar to a finding by Njagi (2014), who found that most teachers were positive towards the support that differentiation provides to achieve lesson objectives. Consequently, the achievement of lesson objectives was reflected in the students' improving performance. These findings also concur with the results discussed by Njagi (2014), who indicated that teachers opting for differentiation indicated that their lessons were interesting to their learners. On the other hand, high expectations from students were controversial as teachers showed varying views about how much to expect from the student when it came to differentiation. This may be attributed to the challenges faced by teachers while implementing differentiated instruction. Bamburg (1994) established that teachers' expectations could determine students, success or failure in class. These expectations, whether high or low, can become a prophecy for students, whose performance will move in the direction of the expectations (Raffini, 1993).

Time is an essential factor in determining the effective implementation of differentiated instruction in the classroom (Van Casteren, Bendig-Jacobs, Wartenbergh-Cras, Van Essen \& Kurver, 2017). Therefore, time, preparation efforts, and the delay in attaining the objectives were among the many factors affecting the respondents' decisions in opting to differentiate. This fact was supported by Jager (2016), who emphasized that teachers struggle to cater to the different needs and interests of students due to time constraints. However, Tomlinson and Imbeau (2010) mentioned that these issues result from the significant changes teachers need to make in their teaching styles and that most can be quickly addressed.

\section{Applying the Principles of Differentiated Instruction}

What information about your students should be examined before implementing differentiated instruction?

The implementation of differentiated instruction calls for a better understanding of students' academic and personal backgrounds (Robinson, 2004). Ernest, Heckman, Hull, \& Carter (2011) pointed out that a pre-assessment of learners' needs is just as crucial as the selfassessment to reflect on the practice effectiveness. Another reality to be considered is that every student comes to the classroom with varied skills and experiences that compel the teacher to verify the students' varied levels of readiness for better implementation of differentiated instruction (Fox \& Hoffman, 2011). When asked what information respondents should have about students to plan their instruction, respondents agreed on language proficiency, readiness, learning styles, interests and skills. Respondents believed that diagnostic tests could reveal the current status of students and assist in varying instruction. Meanwhile, the strengths, and weaknesses of students, providing sufficient input, learner autonomy, and a sense of responsibility contribute to the significant decision of varying instruction as well.

How do you assess your students to obtain the necessary information about their prior knowledge to start differentiating or customising your instruction? 
Teachers continually assess students to see how responsive they are to the materials taught. Assessment is also intended to evaluate students' proficiency levels. Teachers collect data about their students' performance throughout the day through a variety of methods. Students' prior knowledge is part of the many areas to be tested in your classes. Thompson and Zamboanga (2003) pointed out the benefits of assessing students' prior-knowledge, among which is modifying their teaching practice to suit the diversifying class. Cobb, Stallings, Dyer \& Wambler (2014) indicated that "prior knowledge assessments are administered before, or at the start of, training and often consist of paper-based or hands-on evaluations of student knowledge and/or skills". Therefore, when respondents were asked about the means through which they gather information about their students, responses varied; the methods they reported can be classified according to the different types of data collected. Formative data are gathered through mini-tests, short interviews, and oral tests to reveal students' skills and where they can be improved. Respondents also indicated collecting observational data by observing students during interactions, group tasks and activities. This kind of data informs teachers' decisions on the pacing of activities and the amount of scaffolding required. The third type of data, summative data, are collected through written assignments and exam results (Garrison \& Ehringhaus, 2007). The results of these assessments help teachers reflect on the effectiveness of their instructional practices and make appropriate adjustments where needed. Moreover, data collected through the different forms of assessment can help teachers determine the grouping and differentiation of instruction to enhance students' growth.

\section{How do you succeed in meeting your course objectives when differentiating your class instruction?}

By the end of each course, students are expected to achieve certain objectives. Considering the mixed-ability classes and the different course objectives, teachers are challenged to provide differentiated instruction to enhance learning. Koeze (2007) and Luster (2008) emphasized the positive effects of differentiated instructions on students' achievement. Similarly, respondents conveyed multiple levels of success regarding objective attainment while differentiating instruction. One participant declared that modifying materials and activities that are adequate for the different levels helped learners achieve the target objectives. Another participant pointed out that "goal attainment is a bit slower owing to time constraints". Time and class size create more significant challenges to implementing differentiated instruction. In another response regarding how successful the teachers had been in meeting objectives, a participant noted "Pretty well, the class has clear parameters and I stuck to them and encouraged some students to do more". Other respondents agreed that, by modifying tasks and simplifying the instructions, they succeeded in achieving the objectives. Similar results were found in multiple research studies where differentiated instruction practices were able to improve the performance of all students (Fisher, Frey, \& Williams, 2003; Lewis \& Batts, 2005; McTigue \& Brown, 2005; Nugent, 2006; Walker, 2002).

\section{How do you deal with students who are behind in reaching the course objectives?}

A powerful contributor to successful teaching practices is teachers' willingness to walk the extra mile with their students. When flexibility and predictability were two important variables of every class (Tomlinson, 2013), teachers were expected to create a balance to assist 
students who fall behind in attaining course objectives. When respondents were asked how they deal with students who fail to attain some objectives, the majority agreed on giving them extra attention and time. Teachers need to understand the reasons why students struggle while simultaneously finding solutions to get them back on track. It is more useful to plan learning experiences that either scaffold or extend learning for students who need extra support or extra challenges to progress (Tomlinson, 2013).

\section{How do you incorporate differentiated instruction for the whole class?}

Participants indicated that they incorporated differentiated instruction into their classrooms by dividing the students into different groups based on interests and readiness. Some respondents varied the type of activities so they can be accomplished individually, in pairs or in groups. Corley (2005) and Hall at el. (2003) discuss the vital role of flexible grouping in which students are divided into various groups in response to their needs, interests and readiness. One respondent explained that students were given a chance to select topics that matched their interests. Another respondent reported that varying the teaching methods is a form of differentiated instruction, although without specifying how the teaching methods were varied. This was supported by Levy (2008) who asserted that one way does not fit all and teachers are expected to use alternative methods in class. Another respondent stated that differentiation can be accomplished by assigning tasks at varying levels of difficulty. This procedure was discussed by Tomlinson (2000) who stated that teachers can vary the rubrics of tasks. Students' success depends on the use of various approaches that lead them to relate to and process new materials. Overall, the respondents showed a good awareness of the different procedures which facilitate differentiation.

\section{How do you assess each student's achievement with differentiation in mind?}

A teacher's ability to plan an individualized classroom environment is parallel to their ability to create assessment tools to evaluate the outcomes (Hattie, 2009). Students' varying levels of interests, learning styles and readiness require diverse assessment approaches to measure achievement of learning outcomes. Responses yielded in the current study showed teachers were highly aware of the need for diverse assessment approaches. Some respondents reported adjusting the question types along with the appropriate lowering or raising of expectations. One respondent stated that assessment is based on the quality of output and the progress of student performance. Two respondents indicated the use of research-based projects which gives students the freedom to pursue topics of their interest. It was argued that this method responds to students' diversity and acquires them with multiple skills (Blumenfeld et al., 1991). Although it may seem daunting, some teachers responded that they go to the extent of varying the assessment tools to cater to the students' differing capacities, levels and learning outcomes. Tomlinson \& Moon (2013) argued that teachers can manipulate different types of summative assessment to reveal what students have achieved.

\section{Students' Reactions to Differentiating Instruction}

Teachers' attempts to create engaging instruction and elevate learning, although very promising, may be passively received by students. Different factors impact students' views of differentiated learning. According to some survey responses, some students show little appreciation for group work and are less cooperative at times. Lack of awareness of the possible benefits of differentiated instruction hinders their positive perception and, therefore, effective use 
of the varied tasks. However, a good number of respondents highlighted positive student reactions towards differentiation. According to this group of respondents, students felt satisfied with the tasks, activities and content covered. The content was mapped to cover the diversity of students' needs and to cater to those needs. According to some respondents, students appreciate the modifications and adjustments teachers make to address the different abilities in the class.

Autonomy-supportive teaching plays a major role in enhancing inner motivation and aligning it to the classroom activity (Reeve et al., 2002, as cited in Furtak \& Kunter, 2012). This correlates with the respondents' own practices when fostering autonomous learning environments in their classrooms. The respondents emphasized the importance of clarifying the objectives of the tasks when initiating independent learning. Through differentiating instruction to suit different individuals, they claim that goals can be successfully attained. Other respondents suggested modules and a provision of guidelines to ensure the tasks are completed. It is evident from these responses that the teachers attempt to activate students' inner motivation by attending to their needs, interests and preferences (Reeve, 2006), representing the core value of differentiated teaching. However, teachers need to set clear guidelines for how autonomy is practiced in their classrooms to avoid its overlap with controlled teaching.

\section{Recommendations}

Based on the survey results, it can be concluded that teachers are mindful of the potential impact of customising learning by differentiating instruction. They are also aware of the general practices that should pave the way for differentiation in their classrooms. However, teachers report receiving inadequate support where moral support is provided, but structural support is also essential to maintain effective practices for differentiation. The ELL department should seek a way to plan and run professional development sessions to support teachers in building their expertise on this subject. These professional development sessions may educate teachers on introducing differentiation to their students ,so they receive it more positively. The current COVID-19 pandemic informs us of the essential need for blended learning in our institutions. Blended learning may be the solution to the main challenge reported by teachers in implementing differentiated instruction, which is time. In a blended learning environment, teachers can upload various materials, run online sessions and design various assessments through the institution platform. This would save classroom time for the teachers and would be more engaging to students, as privacy is more secure.

\section{Conclusion}

Although all students are expected to achieve the same course objectives, they do not necessarily respond to the same instructional methods. Hence, differentiating instruction in the classroom is no longer an option but necessary in every classroom to ensure successful learning for all. A great deal of research has focused attention on the importance of differentiating instruction in the classroom. The present study examined teachers' perceptions about differentiated instruction and the practices they use to meet the needs of their EFL students. The study revealed that teachers are acquainted with differentiated instruction, but they report receiving inadequate support from their organisation. It was uncovered that teachers practice differentiation of instruction on at least one if not on all three levels of content, process and product (Tomlinson, 2000). Results also indicated that insufficient support from the organisation 
along with students' lack of appreciation for differentiated activities were some of the barriers to successful implementation of differentiated instruction in the classroom.

The current study had some limitations that are worth mentioning. The sample size was relatively small with only 15 respondents. More participants would provide various insights into the practices they implement in their classes. Furthermore, along with the questionnaire, a classroom observation of the participants' practices would be a better indicator of the different activities implemented to cater to the diverse needs and interests of students.

Despite the limitations, this research provides evidence of teachers' awareness of differentiated instruction and suggests further study is needed on the challenges facing the implementation of differentiated instruction.

\begin{abstract}
About the Authors:
Munira Said Al-Siyabi is an assistant lecturer at the University of Technology and Applied Sciences, Rustaq with nine years of experience of teaching English as a second language. Munira completed her MA in TESOL at Leeds University, UK in 2011. Her research interests include teaching and learning in higher education and learner autonomy.
\end{abstract}

ORCID ID: https://orcid.org/0000-0003-0415-5002

Dalal Abdullah Al-Shekaili is a lecturer at the University of Technology and Applied Sciences, Rustaq College of Education. She has nine years of experience in the field of teacher preparation program. Dalal is an MA holder in TESOL from the University of Durham, UK.

ORCID ID:https://orcid.org/0000-0002-9412-9758

\title{
References
}

Abbati, D. G. (2012). Differentiated Instruction: Understanding the personal factors and organizational conditions that facilitate differentiated instruction in elementary mathematics classrooms, University of California, Berkeley. (Unpublished Doctoral dissertation). Retrieved from eScholarship.org.

Amabile, T. M. (1996). Creativity in context: Update to "The Social Psychology of Creativity." Westview Press.

Bamburg, J. (1994). Raising expectations to improve student learning. Oak Brook, IL: North Central Regional Educational Laboratory.

Blumenfeld, P. C. et al. (1991). Motivating Project-Based Learning: Sustaining the Doing, Supporting the Learning. Educational Psychologist. 26(3\&4). 368-398.

Campbell, B. (2009). To-with-by: A three-tiered model for differentiated instruction. New

England Reading Association Journal, 44(2), 7-9. Retrieved from EBSCOhost. (Accession No. 36835958).

Cobb, G., Dyer, J., Stallings, G., \& Wampler, R. (2014). Prior Knowledge Assessment Guide. Arlington, VA: U.S. Army Research Institute for the Behavioral and Social Sciences.

Corley, M. (2005). Differentiated instruction: Adjusting to the needs of all learners. Focus on Basics: Connecting Research and Practice, 7(C), 13-16.

Dodge, J. (2009). 25 Quick Formative Assessments for a Differentiated Classroom. New York, USA: Scolastic. 
Arab World English Journal (AWEJ) Volume 12. Number 1. March 2021

Dunn, R., \& Griggs, S. A. (1998). Learning styles: Link between teaching and learning. In R. Dunn, \& S. Griggs. (Eds.), Learning styles and the nursing profession (pp. 11-23). NLN Press: New York.

Ernest, J., Heckman, K., Hull, K., \& Carter, Sh. (2011). Increasing the teaching efficacy of a beginning special education teacher using differentiated instruction: A case study. International journal of special education, 26(1),191-201.

Fisher, D., Frey, N., \& Williams, D. (2003). It takes us all. Principal Leadership, 4(3), 41-44.

Fox, J., \& Hoffman, W. (2011). The Differentiated Instruction Book of Lists. San Francisco: Jossey-bass.

Furtak, E., \& Kunter, M. (2012). Effects of Autonomy-Supportive Teaching on Student Learning and Motivation. The Journal of Experimental Education, 80(3), 284-316. DOI:10.1080/00220973.2011.573019.

Garrison, C., \& Ehringhaus, M. (2007). Formative and summative assessments in the classroom. Retrieved from http://www.amle.org/Publications/WebExclusive/Assessment/tabid /1120/Default.aspx.

Hall. T., Strangman, N., \& Meyer, A. (2003). Differentiated instruction and implications for UDL implementation. Wakefield, MA: National Center on Accessing the General Curriculum. Retrieved from aem.cast.org.

Hattie, J. (2009). Visible learning. New York: Routledge.

Jager, T. de. (2016). Perspectives of teachers on differentiated teaching in multicultural South African secondary schools. Studies in Educational Evaluation, 53, 115- 121.

Koeze, P. A. (2007). Differentiated instruction: The effect on student achievement in an elementary school. Eastern Michigan University, Michigan. (Doctoral Thesis). Retrieved from https://commons.emich.edu/theses/31

Levy, H. M. (2008). Meeting the needs of all students through differentiated instruction: Helping every child reach and exceed standards. The Clearing House, 81(4), 161- 164. https://doi.org/10.3200/TCHS.81.4.161-164

Lewis, S., \& Batts, K. (2005). How to implement differentiated instruction? Adjust, adjust, adjust. Journal of Staff Development, 26(4), 26-31.

Luster, R. J. (2008). A quantitative study investigating the effects of whole-class and differentiated instruction on student achievement. Walden University. (Unpublished doctoral dissertation). (UMI No: 3320691).

McTighe, J., \& Brown, J. L. (2005) Differentiated Instruction and Educational Standards: Is Detente Possible? Theory Into Practice, 44(3), 234-244.

Moon, T.R. (2005). The Role of Assessment in Differentiation. Theory into Practice, 44 (3), 226- 233.

National Research Council. (1996). National Science Education Standards. Washington, DC: National Academy Press.

Nicolae, M. (2014). Teachers' beliefs as the differentiated instruction starting point: research basis. Procedia - Social and Behavioral Sciences, 128. 426 - 431.

Njagi, M. W. (2014). Teachers' Perspective towards Differentiated Instruction Approach in Teaching and Learning of Mathematics in Kenya. International Journal of Humanities and Social Science, 4(13), 236-241.

Nugent, L. (2006). When technology met accountability. $T H E$ Journal,33(12), 41. https://doi.org/10.1176/pn.41.11.0033. 
Raffini, J. (1993). Winners without losers: Structures and strategies for increasing student motivation to learn. Needham Heights, MA: Allyn and Bacon.

Reeve, J. (2006). Teachers as facilitators: What autonomy-supportive teachers do and why their students benefit. Elementary School Journal, 106 (3), 225-236. https://doi.org/10.1086/501484

Renninger, K. (1998). The roles of individual interest(s) and gender in learning. An overview of research on preschool and elementary school-aged children/students. In L. Hoffmann, A. Krapp, K. Renninger, \& J. Baumert (Eds.), Interest and learning: Proceedings of the Second Conference on interest and gender (pp. 165-175). Kiel, Germany: IPN.

Robison, E. M. (2004). Teacher decision-making in utilising differentiated instruction, (Unpublished Doctoral dissertation). Marywood University, Pennsylvania.

Strassman, B. K. (2005). Differentiated instruction in the English classroom: Content, process, product and assessment. Journal of Adolescent \& Adult Literacy, 48(4), 358-359.

Thompson, R. \& Zamboanga, B. Prior Knowledge and Its Relevance to Student Achievement in Introduction to Psychology. Teaching of Psychology, 30(2):96-101.

Tomlinson, C. A. (2000). Reconcilable differences. Educational Leadership, 58(1), 6-11.

Tomlinson, C. \& Allan, S. (2000). Leadership for Differentiating Schools and Classrooms. Alexandria, Virginia: ASCD.

Tomlinson, C. A. et al. (2003). Journal for the Education of the Gifted, 27 (2-3),119-145.

Tomlinson, C. A. et al. (1997). Becoming architects of communities of learning: Addressing academic diversity in contemporary classrooms. Exceptional Children, 63, 269-282.

Tomlinson, C. A., \& Imbeau, M. B. (2010). Leading and Managing a Differentiated Classroom. Alexandria, VA: ASCD.

Tomlinson, C., \& Moon, T. (2013). Assessment and student success in a differentiated classroom. Alexandria, VA: ASCD.

Van Casteren W., Bendig-Jacobs J., Wartenbergh-Cras F., Van Essen M., \& Kurver B. (2017). Differentiation and Differentiation Skills in Secondary Education. Nijmegen.

Vygotsky, L. S. (1978). Mind in Society: The Development of Higher Psychological Processes. Cambridge, MA: Harvard University Press.

Vygotsky, L. (1986). Thought and language. Cambridge: The MIT Press.

Walker, S. Y. (2002). The survival guide for parents of gifted kids. Minneapolis, MN: Free Spirit Publishing Inc.

Zailinawati AH., Schattner P., \& Mazza D. (2006). Doing a pilot study: why is it essential? Malaysian Family Physician, 1(2\&3), 70-7. 